\title{
Combating Childhood Obesity with an Integrated School Curriculum
}

\author{
Choi YS ${ }^{* 1}$ and Goldstein $\mathrm{MG}^{2}$
}

${ }^{1}$ Departments of Medicine and Pediatrics Womack Army Medical Center, Fort Bragg, NC, USA

${ }^{2}$ Veterans Health Administration, National Center for Health Promotion and Disease Prevention, Durham, NC, USA

*Corresponding author: Choi YS, MD, Departments of Medicine and Pediatrics, Womack Army Medical Center, 2817 Reilly Road, Fort Bragg, NC, USA 28310, Fax: 910-907-7870, Tel: 910-907-6522, E-mail: young.s.choi. civ@mail.mil

Citation: Choi YS, Goldstein MG (2015) Combating Childhood Obesity with an Integrated School Curriculum. J Obes Overweig 1(2): 201. doi: 10.15744/2455-7633.1.201

Received Date: March 20, 2015 Accepted Date: August 22, 2015 Published Date: August 25, 2015

The prevalence of overweight and obesity among US adults is well-documented [1] and lifestyle intervention remains the foundation for all overweight and obesity treatment interventions, even when bariatric surgery is offered [2]. Unfortunately, lifestyle intervention, though clearly a vital part of any obesity treatment, including bariatric surgery, has not been found to be as effective in achieving health benefits as hoped for. Furthermore, not a single study has documented a benefit of lifestyle intervention in reducing cardiovascular events or mortality [3]. For example, the Look AHEAD study randomized 5145 overweight or obese adults with type 2 diabetes, a population at significant risk for cardiovascular events, to an intensive lifestyle weight loss intervention or standard diabetes support. The intended duration of follow-up of 13.5 years was stopped early at 9.6 years based on a futility analysis that showed no difference in cardiovascular outcomes [4]. A recent commentary emphasizes the difficulty in treating established obesity in adults due to the occurrence of biologic mechanisms that maintain the obese state [5]. It is clear that prevention of obesity is the optimal long-term strategy for addressing the adult obesity epidemic.

For the pediatric population, $32 \%$ of all US children are at least overweight [6], while in their military counterparts, the prevalence is $27 \%$ [7]. Given the effect of overweight and obesity on the military population, it is understandable that in a report released by Mission: Readiness/Military Leaders for Kids, childhood obesity was considered a national security issue as obesity is the number one medical reason why applicants fail to qualify for military service [8]. Furthermore, due to the effect of obesity on the overall US population, the most recent survey by the C.S. Mott Children's Hospital National Poll on Children's Health showed that adults ranked childhood obesity as their number one concern [9].

As for adults, the treatment of choice in the pediatric population is lifestyle intervention. However, unlike adults there is very little evidence regarding the effectiveness of non-lifestyle intervention approaches. Unfortunately, due to the lack of consistent methodological rigor and long-term outcomes, it is difficult to identify an evidenced-based intervention approach for lifestyle intervention among children. Therefore, as for adults, prevention of childhood obesity is the optimal strategy [10].

Since over $95 \%$ of children attend schools, a school-based approach to prevention of childhood obesity is sensible from a public health perspective as no other venue offers greater potential to reach this population and there is very little evidence to support an intervention program that does not involve schools [11]. Unfortunately, the evidence for long-term outcomes in the school setting is scant. A 2009 systematic review of school-based interventions found insufficient evidence to assess the efficacy of dietary interventions [12]. Of the 15 studies that reported on physical activity, 5 reported change in BMI and of these, only 2 reported significant changes in boys [12]. A 2012 systematic review and meta-analysis evaluated 6 school-based studies and follow-up for all was 1 year or less [13]. In the 2013 Agency for Healthcare Research and Quality review, 13 US randomized controlled trials (mean of 93 weeks) and 7 US non-randomized controlled trials (mean of 64 weeks) that involved school-based only interventions were reviewed [11]. Of the 13 trials that reported on BMI values (percentile, z-scores or change in overweight or obesity prevalence), only one showed significant change in the intervention group [11]. This latter study randomized 201 African-American girls 8 to 12 years of age to a control vs. an after-school intervention group consisting of 30 minutes of homework time with a healthy snack and 80 minutes of physical activity [14]. This intervention, which achieved a mean attendance of 54\% occurred throughout the year when school was in session. Compared to the control group, the intervention group had a reduced percentage body fat (-2.01), body mass index (-0.45), and visceral adipose tissue as measured by magnetic resonance imaging [14].

The relative lack of consistent and long-term data hampers efforts to implement strategies to prevent or treat childhood obesity. Policy makers, who generally look to the medical profession for assistance on such health matters, find few partnerships. Part of the solution in addressing the burden of obesity is therefore to responsibly navigate through the limitations and constraints imposed by relying on evidence when making policy decisions. When "there is insufficient evidence to conclude" whether interventions are effective, inertia regarding prevention and treatment may set in. For instance, while long-term data for primary 
care-based intervention to address childhood obesity is lacking [13], primary care providers entrusted with the care of children should nonetheless engage with patients, parents and other caregivers to address healthy eating, physical activity and weight issues. Similarly, the lack of robust long-term efficacy outcomes for school-based interventions should not preclude moving forward to address our collective responsibility to promote children's health and well-being.

In spite of this relative lack of evidence, a school-based approach has been advocated by the US Centers for Disease Control and Prevention (CDC) from a policy standpoint [15]. One of the ten strategies promoted by the CDC is to implement a high-quality course of study in health education that meets state or national standards. We strongly support this strategy. However, we believe it is time for an even more aggressive approach: an integrated-school curriculum. For instance, we do not need to wait for evidence to suggest efficacy before we implement an integrated curriculum that advocates appropriate choices and approaches regarding bullying, drug abuse, smoking/tobacco abuse and school violence, the number two through five most important childhood health concerns among US adults [9]. Similarly, an integrated curriculum-based approach to address the number one childhood concern, obesity, is reasonable. Such an approach would incorporate healthy lifestyle education and an emphasis on choices into core curriculum requirements such as STEM (science, technology, engineering, and math).

As an example, the Motivating Adolescents with Technology to CHOOSE Health (MATCH) program has been implemented in $7^{\text {th }}$ grade classes in eastern North Carolina, a region with a high obesity prevalence $[13,16]$. Four year outcomes show impressive results from a single year of intervention. This program integrates conceptual knowledge, health skills, individualized tasks, and motivational strategies with science or health, language arts, math, technology and social studies. For instance, students learn to measure, graph, and plot body mass index or weigh the amount of sugar in a 22 ounce soft drink. Integrating healthy choices into a standard curriculum through programs such as MATCH is an ideal method for addressing the public health imperative of obesity prevention.

It is therefore reasonable to advocate for an integrated approach for childhood obesity, the number one child health concern and a potential "national security" issue. Medical professionals can exert their collective influence by engaging with local school teachers, principals, superintendents, and school board members. This process could be reproduced at other levels, e.g., state boards of education and legislative arms. In this fashion, the entire community shares the responsibility of childhood obesity, not just clinicians, educators or those responsible for after-school programs.

As the co-physician champions of the 2014 Veterans Administration/Department of Defense Clinical Practice Guideline for the Screening and Management of Adult Overweight and Obesity [3], we believe that pediatric intervention is vital to the future health of our military and Veteran population. Therefore, we feel that school-based interventions are a critical element of an effective public health approach to prevent both childhood and adult obesity. Thus, we advocate for widespread adoption of comprehensive integrated school curriculums to address childhood obesity.

The views expressed herein are those of the authors and do not reflect the official policy of the Department of the Army, Department of Defense, Veterans Administration or the U.S. Government.

\section{References}

1. Flegal KM, Carroll MD, Kit BK, Ogden CL (2012) Prevalence of obesity and trends in the distribution of body mass index among US adults, 1999-2010. JAMA 307: 491-7.

2. Jensen MD, Ryan DH, Apovian CM, Ard JD, Comuzzie AG, et al. (2014) 2013 AHA/ACC/TOS guideline for the management of overweight and obesity in adults: a report of the American College of Cardiology/American Heart Association Task Force on Practice Guidelines and The Obesity Society. J Am Coll Cardiol 63: 2985-3023.

3. DOD/VA (2014) Clinical Practice Guideline for Management of Overweight and Obesity.

4. Look AHEAD Research Group, Wing RR, Bolin P, Brancati FL, Bray GA, et al. (2013) Cardiovascular effects of intensive lifestyle intervention in type 2 diabetes. N Engl J Med 369: 145-54.

5. Ochner CN, Tsai AG, Kushner RF, Wadden TA (2015) Treating obesity seriously: when recommendations for lifestyle change confront biological adaptations. Lancet Diabetes Endocrinol 3: 232-4.

6. Odgen CL, Carroll MD, Kit BK, Flegal KM (2010) Prevalence of obesity and trends in body mass index among US children and adolescents, 1999-2010. JAMA 307: 483-90.

7. Choi YS, Berry-Caban C, Stratman R, Fleming JH (2012) Prevalence of high body mass index among children and adolescents at a US military treatment facility, 2008-2009. Prev Chronic Dis 9: doi.org/10.5888/pcd9.120051.

8. Too fat to fight (2010) Mission: Readiness: Military Leaders for Kids, Washington DC, USA.

9. Top 10 U.S. Children's Health Concerns (2014) C.S. Mott Children's Hospital National Poll on Children's Health, Accessed February 18 , 2015.

10. Waters E, de Silva-Sanigorski A, Hall BJ, Brown T, Campbell KJ, et al. (2011) Interventions for preventing obesity in children. Cochrane Database Syst Rev 12: doi: 10.1002/14651858.CD001871.pub3.

11. Wang Y, Wu Y, Wilson RF, Bleich S, Cheskin L, et al. (2013) Childhood obesity prevention programs: comparative effectiveness review and meta-analysis. Comparative Effectiveness Review No. 115. Agency for Healthcare Research and Quality (AHRQ) Publication No. 13-EHC081-EF, USA.

12. Brown T, Summerbell C (2009) Systematic review of school-based interventions that focus on changing dietary intake and physical activity levels to prevent childhood obesity: an update to the obesity guidance produced by the National Institute for Health and Clinical Excellence. Obes Rev 10: $110-41$. 
13. Ho M, Garnett SP, Baur L, Burrows T, Stewart L, et al. (2012) Effectiveness of lifestyle interventions in child obesity: systematic review with meta-analysis. Pediatrics 130: e1647-71

14. Barbeau P, Johnson MH, Howe CA, Allison J, Davis CL, et al. (2007) Ten months of exercise improves general and visceral adiposity, bone, and fitness in black girls. Obesity 15: 2077-85.

15. Make a difference at your school (2015) Centers for Disease Control and Prevention U.S. Department of Health and Human, USA.

16. Lazorick S, Crawford Y, Gilbird A, Fang X, Burr V, et al. (2014) Long-term obesity prevention and the Motivating Adolescents with Technology to CHOOSE Health" $^{\text {tw }}$ program. Child Obes 10: 25-33.

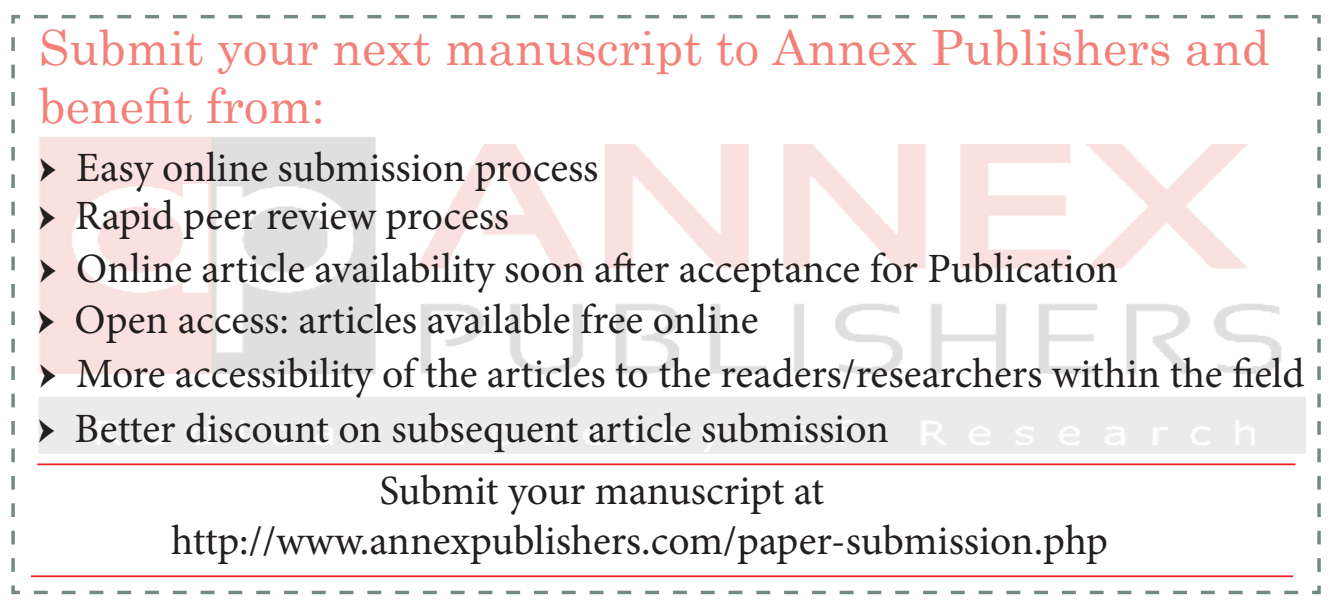

